\title{
Nerve Conduction Study Findings in Ulnar-Median Nerve Intercommunications in the Upper Limb: A
} Short Review

\author{
Santosh Wakode ${ }^{1}$, Naveen Ravi ${ }^{1}$, Suchitra Dube ${ }^{1}$, Naina Wakode ${ }^{2}$ \\ ${ }^{1}$ Department of Physiology, All India Institute of Medical Sciences, Bhopal, Madhya Pradesh, India, ${ }^{2}$ Department of \\ Anatomy, Atal Bihari Vajpayee Government Medical College, Vidisha, Madhya Pradesh, India
}

\begin{abstract}
Intercommunications between ulnar and median nerves in the forearm and hand are a commonly encountered phenomenon. Clinicians should be aware of these communications for better diagnosis and management of the patient, as the clinical presentation can often be misleading. Surgeons should be aware of these anastomoses so as to prevent any iatrogenic injury during the course of treatment. Furthermore, these intercommunications can distort the findings on nerve conduction studies, leading to misinterpretation and misdiagnosis. In the forearm region, there are two prominent median-ulnar anastomoses, namely, Martin-Gruber anastomosis (MGA) and reverse MGA (Marinacci anastomosis). Similarly, in the palm too, there are two major anastomoses, namely, Riche-Cannieu anastomosis and Berrittini anastomosis. Here, in this review, we would like to emphasize on electrophysiological findings that can be observed in the presence of such anastomoses.
\end{abstract}

Key words: Berrittini, Marinacci, Martin-Gruber, median and ulnar communication, median nerve, nerve anastomosis, nerve conduction study, reverse Martin-Gruber, Riche-Cannieu, ulnar nerve

\section{INTRODUCTION}

Median and ulnar nerve intercommunications are very common. ${ }^{[1-3]}$ The vast majority of the individuals with these anastomoses are asymptomatic and go about their daily routines without ever being aware of them. Most of the times, these anastomoses are incidentally detected during cadaveric studies. ${ }^{[4-11]}$ Moreover, some of these nerve intercommunications can be incidentally noticed during surgery. ${ }^{[12]}$ A number of research works on nerve conduction studies (NCS) have also demonstrated that these anomalous

\begin{tabular}{|l|l|}
\hline \multicolumn{2}{|c|}{ Access this article online } \\
\hline Publisher & \multirow{2}{*}{$\begin{array}{l}\text { Website: } \\
\text { www.ijdms.in }\end{array}$} \\
\hline & DOI: 10.30954/IJDMS.1.2020.8 \\
\hline
\end{tabular}

anastomoses can be incidentally detected during routine NCS. . $^{[9,13-16]}$

It has been estimated that up to $91 \%$ of upper limbs can have interconnections between the ulnar and median nerves. ${ }^{[3]}$

On average, there are about 2.8 anastomotic connections involving the median and ulnar nerves per upper limb. ${ }^{[3]}$

It has been suggested that, in the presence of conduction blocks of upper limb nerves, these intercommunications can provide an alternative route for the nerve fibers to supply the hand muscles. ${ }^{[17]}$

These anastomoses are clinically important and have resulted in misdiagnosis during the assessment of nerve injuries ${ }^{[18]}$ and leprosy and entrapment neuropathies. ${ }^{[19-24]}$

Clinically, the presence of these anastomoses in the forearm and hand has been associated with anomalous innervations

\footnotetext{
Address for Correspondence:

Santosh Wakode, Department of Physiology, Medical College Building, Saket Nagar, All India Institute of Medical Sciences, Bhopal - 462 020, Madhya Pradesh, India. Tel: +91-9423446073. E-mail: santosh.physiology@aiimsbhopal.edu.in
} 
of muscle or skin resulting in inconsistent NCS findings observed on electrophysiological studies. ${ }^{[21,25-27]}$

There are also reports suggesting that these anastomoses can be a major factor in inducing complications during surgical procedures. ${ }^{[28]}$

Intercommunications between the median and ulnar in the upper limbs are of four predominant types. These include two in the forearm and two in the palm. They are presented in Table 1.

These intercommunications can lead to misleading clinical findings and misinterpretation of NCS; hence, knowledge of such anastomoses can facilitate in proper diagnosis and management and further prevent any iatrogenic injury.

Nerve conduction study findings of these four median-ulnar intercommunications have been elaborated on this paper.

\section{MARTIN-GRUBER ANASTOMOSIS (MGA)}

The MGA anastomosis arises from the median nerve proximally and joins the ulnar nerve distally in the forearm region. ${ }^{[2,3]}$ It was first described by Martin in 1763 and later on by Gruber in 1870, hence the name MGA. ${ }^{[29]}$

It is estimated that MGA has a prevalence of $19.5 \%{ }^{[2]}$ It is believed that MGA is most often unilateral and present on the right side. ${ }^{[1,30]}$ When MGA is bilateral, it has been linked to Down's syndrome, which is trisomy of the $21^{\text {st }}$ chromosome. ${ }^{[2,31]}$

Crutchfield and Gutmann suggested that MGA can have an autosomal dominant pattern of inheritance. ${ }^{[32]}$

Anatomically speaking, in the majority of the cases, the communicating nerve arises from the anterior interosseous nerve (branch of the median nerve), then runs obliquely, and superficially to the muscles of flexor digitorum superficialis or flexor digitorum profundus. It then runs posterior to the ulnar artery before joining the ulnar nerve ${ }^{[2]}$ [Figure 1].

Oh have classified MGA broadly into Three types, Type 1, Type 2, and Type 3. ${ }^{[3,33]}$

In Type 1, the communicating branch carries motor nerve fibers from the median nerve to ulnar nerve resulting in the innervation of hypothenar muscles. This type has an estimated prevalence of $17.3 \%$. Here, on NCS, on recording from abductor digiti minimi (ADM) muscle, and stimulating ulnar nerve, compound muscle action potential (CMAP) recorded would be greater on proximal (elbow) stimulation compared to distal (wrist) stimulation. ${ }^{[3,33]}$

In Type 2, the communicating branch carries motor nerve fibers from the median nerve to ulnar nerve leading to

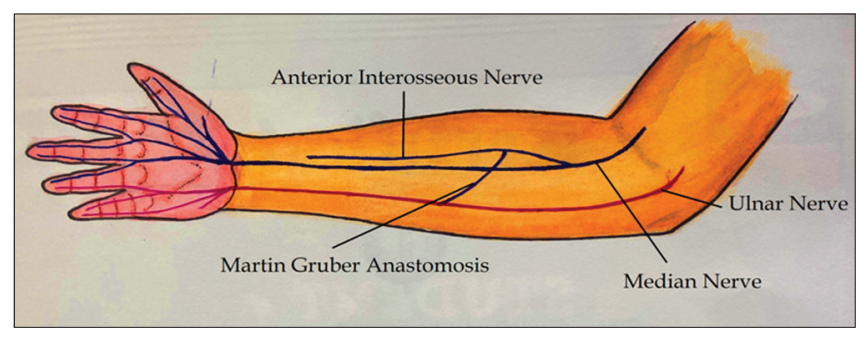

Figure 1: Illustration depicting Martin-Gruber anastomosis (MGA). The MGA anastomosis arises from median nerve proximally and joins the ulnar nerve distally in the forearm region

Table 1: Common median-ulnar intercommunications, their anatomical location, and type of nerve fibers involved

\begin{tabular}{|c|c|c|c|c|}
\hline $\begin{array}{l}\text { Name of the } \\
\text { anastomosis }\end{array}$ & $\begin{array}{l}\text { Proximal } \\
\text { nerve }\end{array}$ & $\begin{array}{l}\text { Distal } \\
\text { nerve }\end{array}$ & Site & $\begin{array}{l}\text { Type of } \\
\text { nerve fibers } \\
\text { crossing over }\end{array}$ \\
\hline Martin-Gruber & Median & Ulnar & Forearm & Motor \\
\hline $\begin{array}{l}\text { Reverse } \\
\text { Martin-Gruber } \\
\text { (Marinacci) }\end{array}$ & Ulnar & Median & Forearm & Motor \\
\hline Richie-Cannieu & Ulnar & Median & Palm & Motor \\
\hline Berrittini & Ulnar & Median & Palm & Sensory \\
\hline
\end{tabular}

innervation of first dorsal interosseous (FDI) muscle. This is the most common type and has a prevalence of about $31 \%$. On NCS, while recording over FDI muscle and stimulating the median nerve, CMAP recorded would be greater on proximal (elbow) stimulation compared to distal (wrist) stimulation. ${ }^{[3,33]}$

Type 3 is the least common among the three and has a prevalence of $0.01 \%$. Here, the communicating branch carries motor nerve fibers from the median nerve to ulnar nerve and results in the innervation of the thenar muscles. Here, on NCS, while recording over abductor pollicis brevis (APB) and stimulating the median nerve, CMAP obtained would be greater on proximal (elbow) stimulation compared to distal (wrist) stimulation. ${ }^{[33]}$

The features of the three types of MGA are summarized in Table 2.

\section{Reverse MGA (RMGA) or Marinacci Anastomosis (MA)}

MA is rarest of all median-ulnar nerve intercommunications and is estimated to have a prevalence of $0.7 \%$. Here, the anastomotic branch arises proximally from ulnar nerve and then traverses the forearm obliquely to join the median nerve distally. ${ }^{[34]}$ This is the reverse of MGA, hence the name RMGA. This communicating branch mostly consists of motor never fibers. ${ }^{[2]}$

Golovchinsky suggested that when an ulnar to median anastomosis is suspected, special care should be taken in the evaluation of motor distal latency of the median nerve with a gradual and slow increase in stimulus voltage. ${ }^{[35]}$ 
Table 2: Types of MGA, their prevalence, anatomical features, and NCS findings

\begin{tabular}{|c|c|c|c|c|c|c|}
\hline \multirow{2}{*}{$\begin{array}{l}\text { Type of } \\
\text { MGA }\end{array}$} & \multirow[t]{2}{*}{ Anatomical features } & \multirow[t]{2}{*}{ Prevalence } & \multicolumn{4}{|c|}{ NCS findings } \\
\hline & & & Nerve & Stimulation site & Recording electrodes & CMAP \\
\hline \multirow[t]{2}{*}{ Type 1} & \multirow{2}{*}{$\begin{array}{l}\text { Motor fibers from median nerve join ulnar nerve } \\
\text { and innervate hypothenar muscles }\end{array}$} & \multirow[t]{2}{*}{$17.3 \%$} & Ulnar & Proximal & ADM & Lesser \\
\hline & & & Ulnar & Distal & ADM & Greater \\
\hline \multirow[t]{2}{*}{ Type 2} & \multirow{2}{*}{$\begin{array}{l}\text { Motor fibers from median nerve join ulnar nerve } \\
\text { and innervate first dorsal interosseous muscle }\end{array}$} & \multirow[t]{2}{*}{$31 \%$} & Ulnar & Proximal & FDI & Greater \\
\hline & & & Ulnar & Distal & FDI & Lesser \\
\hline \multirow[t]{2}{*}{ Type 3} & \multirow{2}{*}{$\begin{array}{l}\text { Motor nerve fibers from median nerve join ulnar } \\
\text { nerve and innervate thenar muscles }\end{array}$} & \multirow[t]{2}{*}{$0.01 \%$} & Median & Proximal & APB & Greater \\
\hline & & & Median & Distal & APB & Lesser \\
\hline
\end{tabular}

FDI: First dorsal interosseous, MGA: Martin-Gruber anastomosis, NCS: Nerve conduction studies, CMAP: Compound muscle action potential, ADM: Abductor digiti minimi, APB: Abductor pollicis brevis

RMGA, also called, MA was first described by Marinacci in 1964. ${ }^{[3]}$ To credit Marinacci, the term "MA" was introduced for the very $1^{\text {st }}$ time by Hopf. ${ }^{[34]}$

In MA, there are motor fibers from ulnar nerve that traverses across the forearm to communicate with median nerve distally, resulting in ulnar innervation of the muscles of the hand that is usually innervated by median nerve ${ }^{[1-3]}$ [Figure 2].

There have been varied reports on the prevalence of MA. A meta-analysis carried out by Roy et al., in which they studied various median and ulnar nerve intercommunications in upper limbs, reported the prevalence of MA to be around $0.7 \%{ }^{\left[{ }^{[1]}\right.}$ Kimura et al. have suggested that the prevalence of MA was $1.3 \%{ }^{[36]}$ However, a study carried out by Meenakshi et al., in India, revealed MA to be much more common. They studied 100 subjects (200 extremities) and found electrodiagnostic evidence of MA in seven limbs, pegging the prevalence at $3.5 \%$, and suggesting that MA is much more common but underreported. ${ }^{[13]}$ In addition, they found MA to be bilateral in 3 out of 4 individuals who had electrodiagnostic evidence of MA. ${ }^{[13]}$

Three major electrodiagnostic criteria have been suggested for the diagnosis of MA, they are followed. ${ }^{[3]}$

1. While recording over the APB muscle, proximal median nerve stimulation results in smaller amplitudes compared to distal stimulation

2. While recording over the ADM, proximal stimulation of ulnar nerve shows higher amplitudes compared to distal stimulation

3. CMAP obtained on proximal stimulation of ulnar while recording over $\mathrm{APB}$, should be at least $50 \%$ the amplitudes obtained on distal stimulation of median while recording over $\mathrm{APB} .{ }^{[3]}$

The characteristics of MA are presented in Table 3.

\section{RICHE-CANNIEU ANASTOMOSIS (RCA)}

RCA represents a neural intercommunication arising from a deep branch of ulnar nerve and joining recurrent branch

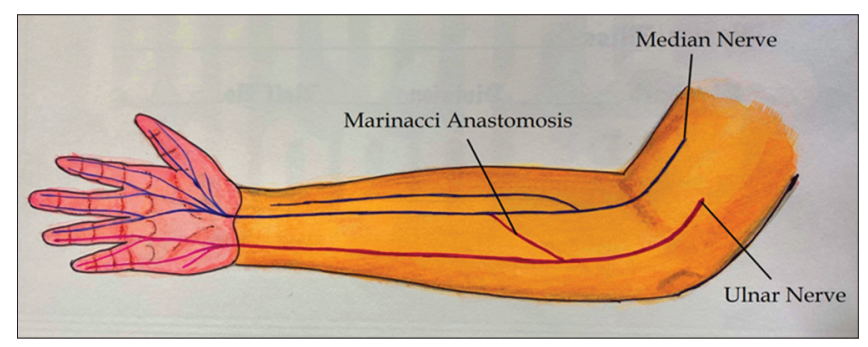

Figure 2: Illustration of Marinacci anastomosis. The anastomotic branch arises proximally from ulnar nerve and then transverses the forearm obliquely to join the median nerve distally

of the median nerve. This anastomotic branch is seen in palm and results in variable ulnar innervation of muscles of palm ${ }^{[1-3]}$ [Figure 3].

Sometimes through this anastomosis, ulnar nerve can end up supplying all the intrinsic muscles of palm. This condition has been referred to as ulnar hand. ${ }^{[37]}$ In some cases, intrinsic muscles of the hand can have dual innervation by both median and ulnar nerves. ${ }^{[37]}$

RCA was described independently by Riche and Cannieu in 1897 from cadaveric studies, hence the name RCA. ${ }^{[1]}$ It has a high prevalence of $55.5 \% .^{[1]}$ It is believed that RCA has an autosomal dominant pattern of inheritance and usually occurs in combination with other median-ulnar intercommunications. ${ }^{[3,38]}$

Electrophysiological studies have shown that in patients with mild carpal tunnel syndrome (CTS), typical findings consistent with RCA can be misinterpreted as severe CTS. This, in turn, can result in unnecessary surgical interventions. In patients with prolonged median sensory and motor latency suggestive of CTS, the presence of RCA should be suspected if median motor amplitudes are worse than median sensory amplitudes. ${ }^{[39]}$

The various aspects of RCA are highlighted in Table 4.

\section{Berrittini Anastomosis (BA)}

BA is named after Pietro Berrettini da Cortona, an Italian painter who first described the communication in $1741 .{ }^{[3]}$ 
Table 3: The anatomical features, prevalence, and NCS findings in MA

\begin{tabular}{|c|c|c|c|c|c|c|}
\hline \multirow{2}{*}{$\begin{array}{l}\text { Type of } \\
\text { anastomosis }\end{array}$} & \multirow{2}{*}{$\begin{array}{l}\text { Anatomical } \\
\text { features }\end{array}$} & \multirow[t]{2}{*}{ Prevalence } & \multicolumn{4}{|c|}{ NCS findings } \\
\hline & & & Nerve & Stimulation site & Recording electrodes & CMAP \\
\hline \multirow{5}{*}{$\begin{array}{l}\text { Marinacci } \\
\text { or reverse } \\
\text { Martin-Gruber }\end{array}$} & \multirow{5}{*}{$\begin{array}{l}\text { Motor fibers from } \\
\text { ulnar nerve join } \\
\text { the median nerve } \\
\text { and innervate } \\
\text { thenar muscles }\end{array}$} & \multirow[t]{5}{*}{$0.7 \%$} & Ulnar & Proximal & ADM & Greater \\
\hline & & & Ulnar & Distal & ADM & Lesser \\
\hline & & & Median & Proximal & APB & Lesser \\
\hline & & & Median & Distal & APB & Greater \\
\hline & & & Ulnar & Proximal & APB & $\begin{array}{l}>50 \% \text { of CMAP obtained on } \\
\text { distal stimulation of median } \\
\text { nerve while recording over APB }\end{array}$ \\
\hline
\end{tabular}

NCS: Nerve conduction studies, CMAP: Compound muscle action potential, ADM: Abductor digiti minimi, APB: Abductor pollicis brevis

Table 4: Anatomical features, prevalence, and NCS findings in RCA

\begin{tabular}{|c|c|c|c|c|c|c|}
\hline \multirow{2}{*}{$\begin{array}{l}\text { Type of } \\
\text { anastomosis }\end{array}$} & \multirow[t]{2}{*}{ Anatomical features } & \multirow[t]{2}{*}{ Prevalence } & \multicolumn{4}{|c|}{ NCS findings } \\
\hline & & & Nerve & Stimulation site & Recording electrodes & CMAP \\
\hline \multirow{4}{*}{$\begin{array}{l}\text { Riche-Cannieu } \\
\text { Anastomosis }\end{array}$} & \multirow{4}{*}{$\begin{array}{l}\text { Motor fibers from deep branch of } \\
\text { ulnar nerve join the recurrent branch } \\
\text { of median nerve, deep in the palm } \\
\text { and innervate thenar muscles }\end{array}$} & \multirow[t]{4}{*}{$0.7 \%$} & Median & Proximal & APB & Low or absent \\
\hline & & & Median & Distal & APB & Low or absent \\
\hline & & & Ulnar & Proximal & APB & Normal \\
\hline & & & Ulnar & Distal & APB & Normal \\
\hline
\end{tabular}

RCA: Riche-Cannieu anastomosis, NCS: Nerve conduction studies, CMAP: Compound muscle action potential, APB: Abductor pollicis brevis

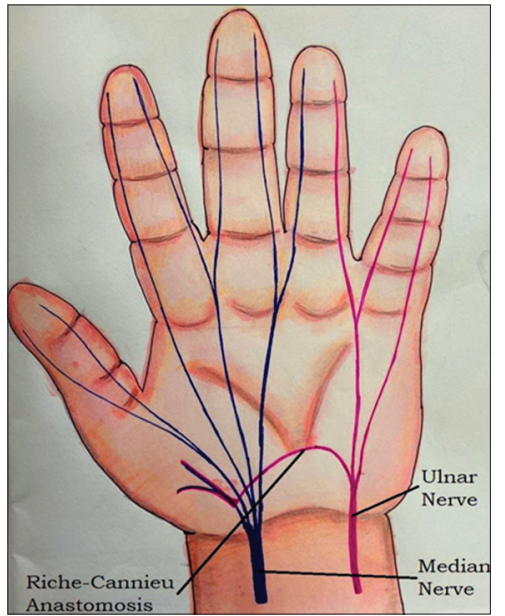

Figure 3: An illustration depicting Riche-Cannieu anastomosis. Here, the anastomotic branch is seen in the palmar region. This branch carrying motor nerve fibers arises from a deep branch of ulnar nerve proximally and then joins median nerve distally. As a consequence of this, thenar muscles are normally supplied by median nerve, end up being innervated by ulnar nerve

BA is also known as superficial palmar communication and is a pure sensory communication. ${ }^{[2,3]}$ This neural communication commonly arises from the fourth common digital nerve (branch of ulnar nerve) at the distal edge of transverse carpal ligament and runs obliquely to join with the third common digital nerve (branch of the median nerve) distally ${ }^{[2,3]}$ [Figure 4].

BA is frequently encountered in cadaveric dissections. ${ }^{[7,40]}$

$\mathrm{BA}$ is reported to have a very high prevalence which is pegged at $60.9 \%$ and because of this, BA is generally considered to be a normal anatomical structure rather than a variation. ${ }^{[1-3]}$ $\mathrm{BA}$ is said to be bilateral $60.5 \%$ of the time. ${ }^{[1]}$

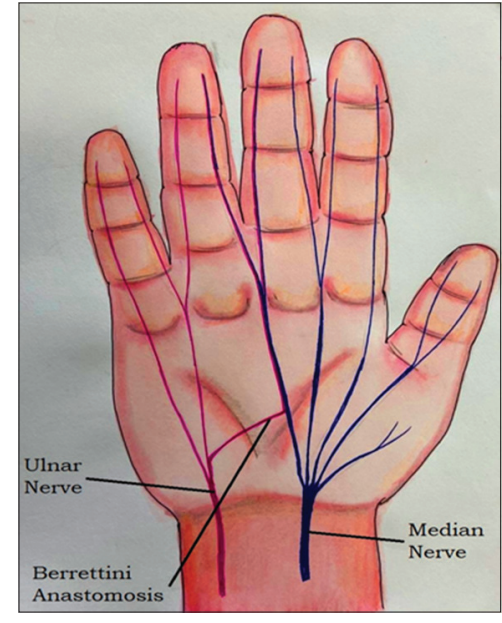

Figure 4: Diagrammatic depiction of Berrettini Anastomosis. This pure sensory neural communication commonly arises from the fourth common digital nerve (branch of ulnar nerve) proximally and runs obliquely to join with the third common digital nerve (branch of the median nerve) distally

BA can be broadly classified into three varieties;

1. A sensory neural branch arising from ulnar nerve in palm and communicating with median nerve in palm. This is referred to BA Type $l$ and is believed to be the commonest of BA types with an estimated prevalence of $86.2 \%$

2. A sensory branch in palm arising from median nerve and communicating with ulnar nerve. This represents BA Type 2 and has a prevalence of $9.4 \%$

3. BA Type 3 has the least prevalence of $4.4 \%$ and represents a diffuse interconnection between median and ulnar nerves in palm. ${ }^{[1]}$

It is believed that BA cannot be studied using NCS techniques. ${ }^{[33]}$ There are two major reasons provided for this 
1. The number of nerve fibers present in the anastomotic branch is highly variable and often very few in number. This hinders any reasonable recording of sensory nerve action potential (SNAP)

2. It is impossible to record the SNAP on only one side of a digit. ${ }^{[3,33]}$

However, a recent study carried out by Seidel at al. suggests that BA can frequently be encountered in NCS. ${ }^{[14]}$ They were able to demonstrate NCS findings of BA in 34\% of the individuals that they tested. Out of these individuals, it was found to be bilateral in $9.5 \%$. They believe that low number of axons involved in the anastomosis, baseline interference, thickness of skin epidermis, and calluses might interfere with recording SNAPs. ${ }^{[14]}$

The anastomoses as described above can lead to varied clinical presentation causing misinterpretation of clinical signs and symptoms, leading to misdiagnoses and can impact the interpretation of NCS. Knowledge of these anastomoses is of relevance for anatomists as they can be encountered during routine cadaveric studies. They are of significance to neurologists and physiologists performing NCS, as the study findings can be misinterpreted as an abnormality. Finally, they are of relevance to clinicians particularly surgeons and orthopedicians to prevent any possible iatrogenic injury that can result from interventions and treatment protocols.

\section{CONCLUSION}

Familiarity of these various nerve anastomoses involving median and ulnar nerves in upper limbs is essential to prevent misdiagnosis, iatrogenic injuries, and misinterpretation of NCS findings.

\section{DISCLOSURE}

All figures in the manuscript were hand made by Dr. Naveen Ravi and Dr. Santosh Wakode.

\section{REFERENCES}

1. Roy J, Henry BM, Pekala PA, Vikse J, Saganiak K, Walocha JA, et al. Median and ulnar nerve anastomoses in the upper limb: A meta analysis. Muscle Nerve 2016;54:36-47.

2. Smith J, Siddiqui S, Ebraheim N. Comprehensive summary of anastomoses between the median and ulnar nerves in the forearm and hand. J Hand Microsurg 2018;11:1-5.

3. Martin S, Schauer K, Czyrny J, Ablove R. Electrophysiological findings in common median-ulnar nerve interconnections and their clinical implications. J Hand Surg 2019;44:884-94.

4. Seidel M, Seidel G, Hakopian D, Hornbach E, Andary M. Electrodiagnostic evidence of Berrettini anastomosis. J Clin Neurophysiol 2018;35:133-7.

5. Nakashima T. An anatomic study on the Martin-Gruber anastomosis. Surg Radiol Anat 1993;15:193-5.

6. Kaur N, Singla RK, Kullar JS. Martin-Gruber anastomosis-a cadaveric study in North Indian population. J Clin Diagn Res 2016;10:AC09-11.

7. Kaur N, Singla RK, Kullar JS. Cadaveric study of berretini communications in North Indian population. J Clin Diagn Res 2016;10:AC07-9.

8. Caetano EB, Vieira LA, Neto JJ, Caetano MF, Sabongi RG. Richécannieu anastomosis: Structure, function, and clinical significance. Rev Bras Ortop (Sao Paulo) 2019;54:564-71.

9. Hefny M, Sallam A, Abdellatif M, Okasha S, Orabi M. Electrophysiological evaluation and clinical implication of MartinGruber anastomosis in healthy subjects. J Hand Surg Asian Pac Vol 2020;25:87-94.

10. Sirasanagandla S, Patil J, Potu B, Nayak B, Shetty S, Bhat K. A rare anatomical variation of the Berrettini anastomosis and third common palmar digital branch of the median nerve. Anat Sci Int 2013;88:163-6.

11. Hodzic R, Hodzic M, Iljazovic E, Piric N, Zukić S. The incidence and characteristics of marinacci anastomosis: An anatomical study. Int J Innov Res Med Sci 2020;5:100-2.

12. Stančić M, Burgić N, Mićović V. Marinacci communication. J Neurosurg 2000;92:860-2.

13. Sundaram SM, Sundar B, Arunkumar MJ. Marinacci communication: An electrophysiological study. Neurophysiology 2003;114:2334-7.

14. Seidel G, Seidel M, Hakopian D, Alabdulkarim M, Rahman A, Andary M, et al. Frequency of electrodiagnostically measurable Berrettini anastomosis. J Clin Neurophysiol 2020;37:214-9.

15. Pasutharnchat N, Amornvit J, Taychargumpoo C, Santananukarn M. Mid-palm recording technique, a new electrodiagnostic approach in Martin-Gruber anastomosis. Clin Neurophysiol Pract 2020;5:79-82.

16. Saba E, Saba A. Electrophysiological study of Martin-Gruber anastomosis in a sample of Egyptians. Egypt Rheumatol Rehabil 2017;44:153-8.

17. Yang H, Gil Y, Kim S, Bang J, Choi H, Lee H. From the brachial plexus to the hand, multiple connections between the median and ulnar nerves may serve as bypass routes for nerve fibres. J Hand Surg Eur Vol 2016;41:648-56.

18. Tubbs RS, Loukas M, Shoja MM, Doyle S, Wellons JC $3^{\text {rd }}$. Retained hand function following transection of the ulnar nerve. Bratisl Lek Listy 2008;109:281-2.

19. Uchida Y, Sugioka Y. Electrodiagnosis of Martin-Gruber connection and its clinical importance in peripheral nerve surgery. J Hand Surg Am 1992;17:54-9.

20. Isaković E, Delić J, Bajtarević A. Martin-Gruber anastomosis and transposition in cubital tunnel. Bosn J Basic Med Sci 2007;7:71-3.

21. Kingery WS, Wu PB, Date ES. An unusual presentation of a traumatic ulnar mononeuropathy with a Martin-Gruber anastomosis. Muscle Nerve 1996;19:920-2.

22. Kómár J, Szalay M, Máté A. A disease pattern simulating a cubitocarpal double-tunnel syndrome due to anastomosis after Martin-Gruber (author's transl). Fortschr Neurol Psychiatr Grenzgeb 1980;48:612-5.

23. Marras C, Midroni G. Proximal Martin-Gruber anastomosis mimicking ulnar neuropathy at the elbow. Muscle Nerve 1999;22:1132-5.

24. Rubin DI, Dimberg EL. Martin-Gruber anastomosis and carpal tunnel syndrome: [Corrected] morphologic clues to identification. Muscle Nerve 2010;42:457-8.

25. Amoiridis G. Median-ulnar nerve communications and anomalous innervation of the intrinsic hand muscles: An electrophysiological study. Muscle Nerve 1992;15:576-9.

26. Gutmann L. AAEM minimonograph \#2: Important anomalous innervations of the extremities. Muscle Nerve 1993;16:339-47.

27. Van Dijk JG, Bouma PA. Recognition of the Martin-Gruber anastomosis. Muscle Nerve 1997;20:887-9.

28. Riechers RG $2^{\text {nd }}$, Landau ME, Farber G, Campbell WW. Damage to sensory fibers in a Martin-Gruber anomaly after biceps tendon repair. J Clin Neuromuscul Dis 2005;6:162-6. 
29. Cavalheiro CS, Filho MR, Pedro G, Caetano MF, Vieira LA, Caetano EB. Clinical repercussions of Martin-Gruber anastomosis: Anatomical study. Rev Bras Ortop 2016;51:214-23.

30. Tountas CP, Bergman RA. Anatomic Variations of the Upper Extremity. New York, Edinburgh, London, Melbourne, Tokyo: Churchill Livingstone; 1993.

31. Srinivasan $\mathrm{R}$, Rhodes $\mathrm{J}$. The median-ulnar anastomosis in normal and congenitally abnormal fetuses. Arch Neurol 1981;38:418-9.

32. Crutchfield CA, Gutmann L. Hereditary aspects of medianulnar nerve communications. J Neurol Neurosurg Psychiatry 1980;43:53-5.

33. Oh SJ. Clinical Electromyography: Nerve Conduction Studies. $3^{\text {rd }}$ ed. Philadelphia, PA: Lippincott Williams \& Wilkins; 2003.

34. Hopf HC. Forearm ulnar-to-median nerve anastomosis of sensory axons. Muscle Nerve 1990;13:654-6.

35. Golovchinsky V. Ulnar-to-median anastomosis and its role in the diagnosis of lesions of the median nerve at the elbow and the wrist. Electromyogr Clin Neurophysiol 1990;30:31-4.

36. Kimura I, Ayyar DR, Lippmann SM. Electrophysiological verification of the ulnar to median nerve communications in the hand and forearm. Tohoku J Exp Med 1983;141:269-74.

37. Loukas M, Abel N, Tubbs RS, Matusz P, Zurada A, Cohen-Gadol A. Neural interconnections between the nerves of the upper limb and surgical implications. J Neurosurg 2011;114:225-35.

38. Boland RA, Krishnan AV, Kiernan MC. Riche-Cannieu anastomosis as an inherited trait. Clin Neurophysiol 2007;118:770-5.

39. Wali A, Ahmed R, Khan S. Electrophysiological evidence of the Riche-Cannieu anastomosis in the hand and its diagnostic implications; 2 case reports. Clin Neurophysiol Pract 2016;2:8-11.

40. Stančić M, Mićović V, Potoćnjak M. The anatomy of the Berrettini branch: Implications for carpal tunnel release. J Neurosurg 1999;91:1027-30.

How to cite this article: Wakode S, Ravi N, Dube S, Wakode N. Nerve Conduction Study Findings in Ulnar-Median Nerve Intercommunications in the Upper Limb: A Short Review. Int J Dent Med Spec 2020;7(1):32-37.

Source of Support: None; Conflicts of Interest: None 